\title{
Control of Bouncing in MEMS Switches Using Double Electrodes
}

\author{
Farhan Abdul Rahim ${ }^{1}$ and Mohammad I. Younis ${ }^{1,2}$ \\ ${ }^{1}$ Physical Science and Engineering Division, King Abdullah University of Science and Technology (KAUST), \\ Thuwal 23955-6900, Saudi Arabia \\ ${ }^{2}$ Department of Mechanical Engineering, State University of New York at Binghamton, Binghamton, 13902 NY, USA \\ Correspondence should be addressed to Mohammad I. Younis; myounis@binghamton.edu
}

Received 19 April 2016; Revised 26 June 2016; Accepted 27 June 2016

Academic Editor: Zhike Peng

Copyright (C) 2016 F. Abdul Rahim and M. I. Younis. This is an open access article distributed under the Creative Commons Attribution License, which permits unrestricted use, distribution, and reproduction in any medium, provided the original work is properly cited.

\begin{abstract}
This paper presents a novel way of controlling the bouncing phenomenon commonly present in the Radio Frequency Microelectromechanical Systems (RF MEMS) switches using a double-electrode configuration. The paper discusses modeling bouncing using both lumped parameter and beam models. The simulations of bouncing and its control are discussed. Comparison between the new proposed method and other available control techniques is also made. The Galerkin method is applied on the beam model accounting for the nonlinear electrostatic force, squeeze film damping, and surface contact effect. The results indicate that it is possible to reduce bouncing and hence beam degradation, by the use of double electrodes.
\end{abstract}

\section{Introduction}

Microelectromechanical systems (MEMS) switches have been widely seen as a potential replacement for complementary metal-oxide semiconductor (CMOS) based switches due to their lower leakage current, higher reliability, and better resistance to radiation and hazards [1]. However, a major problem in mechanical switches is the phenomenon of bouncing, which has been seen to drastically reduce both the switch life and its performance [1]. Several authors have modeled bouncing using many different methodologies. McCarthy et al. [2] and Do et al. [3] used Euler Bernoulli beam model to simulate the beam dynamics including its bouncing. Bouncing was modeled by using a spring at the tip of the cantilever to capture the tip-substrate interaction. Wang and Asokanthan [4] presented an asperitybased contact model to model the bouncing effect in MEMS cantilever switches. Theoretically, the Galerkin method was applied on Euler Bernoulli beam model accounting for the squeeze film damping force. Experimental verification using a switch prototype has been presented. Several studies simulated bouncing using lumped parameter models [57]. Peschot et al. [8] tested experimentally the dynamics during the bouncing and found it to be highly nonlinear phenomenon and hence may not be easily explained using linear mechanical bounce model. Jain et al. [9] introduced the use of resistive braking to slow down the beam velocity by attaching an appropriate resistor in series with the switch. Furthermore, they discussed using different shapes on the landing pad of the switch to reduce the bouncing velocity.

Input pulse shaping has been also proposed to minimize bouncing. Wong and Lai [10] discussed the different merits of different dual pulse waveforms and their robustness with respect to changes in the switch parameters. Selection of parameters for the input waveform is a task that has been discussed by several authors. Blecke et al. [6] discussed a learning control actuation waveform that can iteratively reduce bouncing by refining the timing of the input pulse to obtain soft landing.

On the other hand, Do et al. [3] developed an analytical method based on energy consideration for selecting the parameters of the dual pulse wave. Spasos and Nilavalan [11] presented description of two techniques to control bouncing: the charge control (resistive damping) and the voltage control. Voltage control is based on an open loop statistical method to control bouncing called the Taguchi's optimization technique. Tung et al. [12] modeled the bouncing using reduced order modeling and accounting for squeeze film 


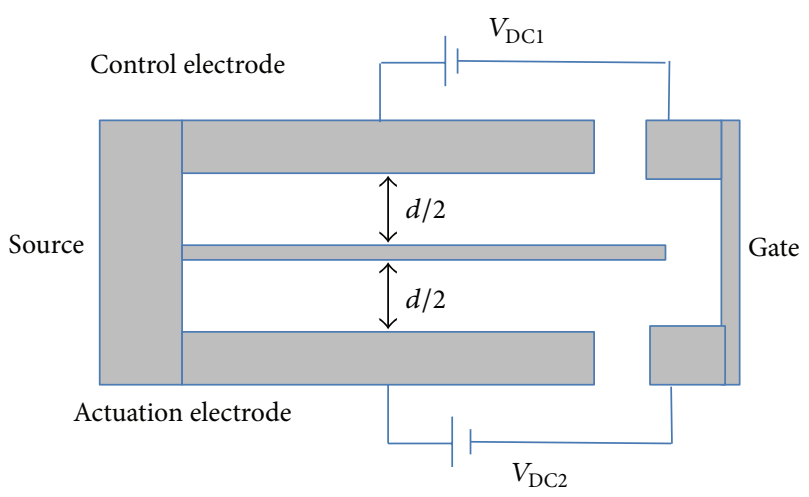

FIGURE 1: Schematic of a double-electrode beam configuration.

damping. The final simulation and testing showed that using two modes in the simulation captures the real dynamics of the system as the bouncing has several short spaced impacts during the actual impact. The transient excitation of the second mode can be thus accurately captured by using a second mode in the reduced order model. The authors showed the influence of contact stiffness and actuation voltage on the final bouncing characteristics. A double-electrode switch was designed by Dadgour et al. [13] to form a universal Negative And (NAND) and a Negative OR (NOR) gate. Such a doubleelectrode design is similar to the configuration under study in this work.

In previous works, delayed feedback controllers have been proposed to stabilize MEMS resonators and make them more immune to dynamic disturbances [14-17]. The technique was based on modifying the electrostatic force to include a delayed velocity or displacement with the delay equal to half of the natural period of the resonator. Such technique however is hard to implement for switches during bouncing since the motion is not necessarily periodic. Yagubizade and Younis [18] developed and studied the effect of the nonlinear squeeze film damping on MEMS microbeams undergoing large motion and during mechanical shock.

This paper presents a new method to control bouncing of switches by implementing a double-electrode configuration for actuation and control. Using a lumped parameter and continuous beam models, the new method will be demonstrated by simulations based on several practical case studies.

\section{Modelling the System}

The modeling of the double-electrode beam is done using both lumped parameter and beam models (Figures 1 and 2). The two models are discussed here with the relevant parameters taken for each.

2.1. Lumped Parameter Model. The equation of a motion of a switch sandwiched between two electrodes can be written as [19]

$$
m \ddot{x}+c \dot{x}+k x=\frac{\varepsilon A}{2}\left(\frac{V_{\mathrm{DC}_{1}}^{2}}{(d-x)^{2}}-\frac{V_{\mathrm{DC}_{2}}^{2}}{(d+x)^{2}}\right)^{2} .
$$

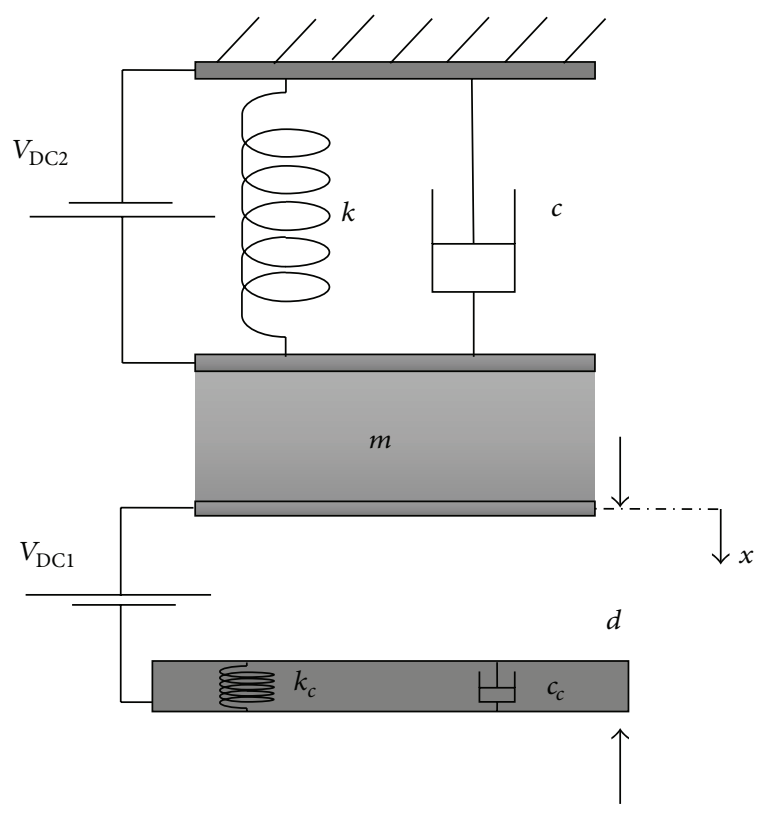

FIGURE 2: Equivalent lumped mass model representation.

Normalizing by $m$ yields

$$
\ddot{x}+2 \zeta w_{f} \dot{x}+w_{f}^{2} x=K_{e}\left(\frac{V_{\mathrm{DC}_{1}}^{2}}{(d-x)^{2}}-\frac{V_{\mathrm{DC}_{2}}^{2}}{(d+x)^{2}}\right),
$$

where $w_{f}=\sqrt{k / m}, c / m=2 \zeta w_{f}$.

Note that subscript $f$ means free (not in contact with the substrate). The values for $k$ and $c$ are adjusted depending on whether there is a contact with the substrate or not; hence the corresponding variables for (2) will also vary. Hence, $w_{f}$ is changed to $w_{c}$ and $\zeta$ to $\zeta_{c}$, which refer to the natural frequency and damping ratios in the presence of contact with the substrate, respectively.

2.2. Beam Model. For the beam model, the Euler Bernoulli equation is solved using the Galerkin method to obtain a reduced order model [19]. A single mode, the first mode, is chosen for the simulation to allow for comparison between the beam model and the lumped parameter model. As before, the dynamics of the beam will be split into contact and noncontact regimes.

To obtain the reduced order model, the following beam equation is assumed:

$$
\frac{\partial^{2}}{\partial x^{2}}\left(E I \frac{\partial^{2} w}{\partial x^{2}}\right)+\rho A \frac{\partial^{2} w}{\partial t^{2}}+c \frac{\partial w}{\partial t}=F
$$

where $E$ is Young's modulus, $I$ is the second moment of inertia of the cross section, $A$ is cross-sectional area, $w(x, t)$ is the beam deflection, $x$ is position on the beam, $t$ is time, and $F$ is the external applied force. 
Using the Galerkin method, the displacement is assumed to be of form

$$
w(x, t)=\sum_{1}^{n} \phi(x) u(t),
$$

where $n$ is the number of modes.

For the free mode (when the beam is not in contact with the substrate), the following boundary conditions are used:

$$
\begin{aligned}
\phi(0) & =0, \\
\phi^{\prime}(0) & =0, \\
\phi^{\prime \prime}(l) & =0, \\
E I \phi^{\prime \prime \prime}(l) & =0 .
\end{aligned}
$$

Similarly, for the contact mode (when the beam is in contact with the substrate), a linear spring is assumed to be at the contact point, and hence the shear force boundary condition present in the above system is replaced with a linear spring force. The new boundary conditions are of the form

$$
\begin{aligned}
\phi(0) & =0, \\
\phi^{\prime}(0) & =0, \\
\phi^{\prime \prime}(l) & =0, \\
\phi^{\prime \prime \prime}(l)-R_{t} \phi(l) & =0,
\end{aligned}
$$

where

$$
R_{t}=\frac{k_{s} l^{3}}{E I}
$$

and $k_{s}$ is the spring stiffness coefficient of the substrate.

The system was modeled both with the case of a constant damping coefficient and in the case of a nonlinear squeeze film damping $[18,19]$.

The nonlinear equation governing the pressure variation $P$ underneath the moving structure of gap width $H$ can be written as

$$
\begin{gathered}
\frac{\partial}{\partial x}\left(H^{3} P \frac{\partial P}{\partial x}\right)+\frac{\partial}{\partial y}\left(H^{3} P \frac{\partial P}{\partial y}\right) \\
=12 \mu\left(H \frac{\partial P}{\partial t}+P \frac{\partial H}{\partial t}\right),
\end{gathered}
$$

where $\mu$ is the viscosity coefficient of the air.

Solving the Reynolds equation and assuming the pressure across the width ( $y$ axis) is more dominant than across the length ( $x$ axis), we obtain the following effective force due to squeeze film damping:

$$
F_{s q f d}=\int_{-b / 2}^{b / 2} \frac{6 \mu}{d^{3}} \frac{\partial w}{\partial t}\left(y^{2}-\frac{b^{2}}{4}\right) d y=-\frac{b^{3} \mu}{d^{3}} \frac{\partial w}{\partial t},
$$

where $c=-b^{3} \mu / d^{3}$. To account for nonlinearity of the squeeze film damping [19] we assume

$$
c=\frac{b^{3} \mu}{[d-w(x, t)]^{3}} .
$$

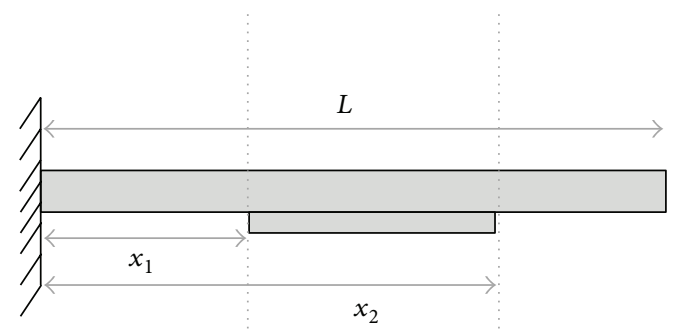

Figure 3: Partial electrode configuration.

Since it is common for beams to have partial electrode instead of complete coverage over the entire length of the beam (Figure 3), the forcing term becomes

$$
F=\frac{\epsilon b V_{\mathrm{DC}}^{2}\left[u\left(x-x_{1}\right)-u\left(x-x_{2}\right)\right]}{2\left(d-w(x, t)^{2}\right)}
$$

where $u\left(x-x_{1}\right)$ and $u\left(x-x_{2}\right)$ are the unit step functions.

The forcing term for the double-electrode system is given in (12). Note that $V_{\mathrm{DC}_{1}}$ and $V_{\mathrm{DC}_{2}}$ refer to actuation and control voltages, respectively. The electrostatic force is defined as

$$
F_{e}=\frac{V_{\mathrm{DC}_{1}}^{2}}{(d-w(x, t))^{2}}-\frac{V_{\mathrm{DC}_{2}}^{2}}{(d+w(x, t))^{2}} .
$$

For convenience, we normalize the system equations using the following parameters:

$$
\begin{aligned}
\widehat{w} & =\frac{w}{d}, \\
\widehat{x} & =\frac{x}{l}, \\
\widehat{t} & =\frac{t}{T},
\end{aligned}
$$

where $T=\sqrt{\rho b h l^{4} / E I}$.

The nondimensional equation of motion then becomes

$$
\begin{gathered}
\frac{\partial^{4} w}{\partial x^{4}}+\frac{\partial^{2} w}{\partial t^{2}}=\alpha_{2}\left(\frac{V_{\mathrm{DC}_{1}}^{2}}{(1-w(x, t))^{2}}-\frac{V_{\mathrm{DC}_{2}}^{2}}{(1+w(x, t))^{2}}\right) \\
\cdot\left(u\left(x-x_{1}\right)-u\left(x-x_{2}\right)\right)-\frac{c_{\mathrm{non}}}{(1-w(x, t))^{3}} \frac{\partial w}{\partial t},
\end{gathered}
$$

where $\alpha_{2}=6 \varepsilon l^{4} / E h^{3} d^{3}$ and $c_{\text {non }}=12 c l^{4} / E T b h^{3}$.

To avoid a complex Taylor expansion of the terms in the denominator which may require up to 20 terms, we multiply both sides by the common denominator, $(1+w)^{2}(1-w)^{3}$, and expand. Hence, after applying the one-mode Galerkin procedure, the final outcome of the modal equation becomes 


$$
\begin{aligned}
\ddot{u}+ & w_{\mathrm{non}}^{2} u+c_{\mathrm{non}} \dot{u} \frac{\left(\int_{0}^{1}\left(\varphi^{2}+2 u \varphi^{3}+u^{2} \varphi^{4}\right) d x\right)}{D}=\alpha_{2} \\
\cdot & \frac{\left(\left(V_{\mathrm{DC}_{2}}^{2}-V_{\mathrm{DC}_{1}}^{2}\right)\left(u^{3} \int_{x_{1}}^{x_{2}} \varphi^{4}-\int_{x_{1}}^{x_{2}} \varphi\right)-\left(3 V_{\mathrm{DC}_{2}}^{2}+V_{\mathrm{DC}_{1}}^{2}\right)\left(u^{2} \int_{x_{1}}^{x_{2}} \varphi^{3}-u \int_{x_{1}}^{x_{2}} \varphi^{2}\right)\right)}{A D} \alpha_{2} \\
& \frac{\left(\left(V_{\mathrm{DC}_{2}}^{2}-V_{\mathrm{DC}_{1}}^{2}\right)\left(u^{3} \int_{x_{1}}^{x_{2}} \varphi^{4}-\int_{x_{1}}^{x_{2}} \varphi\right)-\left(3 V_{\mathrm{DC}_{2}}^{2}+V_{\mathrm{DC}_{1}}^{2}\right)\left(u^{2} \int_{x_{1}}^{x_{2}} \varphi^{3}-u \int_{x_{1}}^{x_{2}} \varphi^{2}\right)\right)}{D}
\end{aligned}
$$

where $D$ is expressed as

$$
\begin{aligned}
D & =\left(-u^{5} \int_{0}^{1} \varphi^{7} d x+u^{4} \int_{0}^{1} \varphi^{6} d x+2 u^{3} \int_{0}^{1} \varphi^{5} d x\right. \\
& \left.-2 u^{2} \int_{0}^{1} \varphi^{4} d x-u \int_{0}^{1} \varphi^{3} d x+\int_{0}^{1} \varphi^{2} d x\right) .
\end{aligned}
$$

Although bouncing is simulated through the use of the above equation, which accounts for the nonlinear squeeze film damping, for comparison with literature, the equation is shown below for the case of a linear constant damping coefficient

$$
\begin{aligned}
& \ddot{u}+w_{\text {non }}^{2} u+c_{\text {non }} \dot{u}\left(u^{4} \int_{0}^{1} \varphi^{6} d x+u^{2} \int_{0}^{1} \varphi^{4} d x\right. \\
& \left.+\int_{0}^{1} \varphi^{2} d x\right)=\alpha_{2}\left[\left(V_{\mathrm{DC}_{1}}^{2}-V_{\mathrm{DC}_{2}}^{2}\right)\right. \\
& \quad \cdot\left(u^{4} \int_{x_{1}}^{x_{2}} \varphi d x+u^{2} \int_{x_{1}}^{x_{2}} \varphi^{3} d x\right)+\left(V_{\mathrm{DC}_{1}}^{2}+V_{\mathrm{DC}_{2}}^{2}\right) \\
& \cdot(2 u \varphi)] .
\end{aligned}
$$

\section{Results}

Simulations were run for both the lumped parameter model and the beam model. The first target of the simulation is to obtain the bouncing dynamics of the switch using (2) and (15). Later, the dynamic response of the beam model is compared to other well-known pulses in literature. A detailed study of the effect of different parameters on the switch dynamics is also performed.

3.1. Bouncing and Control Using Lumped Parameter Model. To simulate bouncing, the damping term and the stiffness term are varied when the beam comes into contact with the substrate. The parameters used to model the beam are taken from [5] and are given in Table 1.

Figure 4 shows the simulation result of the uncontrolled bouncing displacement and velocity profile obtained through the integration of (2) in time using Runge-Kutta scheme. The dotted horizontal line represents the position of the substrate (or dielectric layer). The high stiffness of the substrate in the model only allows for small penetration.

Tuning to obtain the best possible result (i.e., lowest landing velocity and landing time) is a tedious process. However this process can be made simpler by discussing the effect of some key parameters that affect the switch dynamics. These include the actuation voltage, the control voltage, the pulse width (duration of application of the control voltage), and pulse position (start of the control voltage). Also, it is important to point out that most of these parameters are influenced by each other. For example, variation in the pulse width will not allow for any noticeable change in the landing time and landing velocity if the application of the control pulse occurs after the first contact between the tip and the substrate.

The values of actuation, control voltages, and the pulse width are given in Table 2.

From Figures 5 and 6 , it is evident that pulse position is an important parameter and fairly intuitive. For instance, applying the control voltage after the initial landing has occurred will not change the landing time on velocity. Also, applying the control pulse before the landing will increase the landing time but reduce the landing velocity.

Actuation voltage and control voltage changes are also studied. The parameters used in the simulation are given in Table 3.

Figures 7-8 show the result of changing the actuation voltage. The results are quite intuitive and show that increasing actuation voltage can allow for reduction in landing time while sacrificing velocity reduction.

However, further reduction in velocity can be achieved for negligible change to landing times by applying the control voltage pulse in a noncontinuous fashion (as in Figure 9). For example, for the duration of the application of the control wave, the actuation voltage is dropped to zero. Figure 9 demonstrates such an application.

These signal values represent the application of the control voltage and actuation voltage for the specified time periods. Using a similar application, the landing velocity curve is found to be as shown in Figure 10.

It is seen in Figure 10 that applying a noncontinuous actuation voltage improves overall velocity characteristics. A velocity of around $0.073 \mathrm{~m} / \mathrm{s}$ can be reached, which provides 
TABLE 1: The parameters used in the lumped parameter model based on the case study done in [5]. In the table, the word "free" means without contact (with subscript $f$ ) while $w_{c}$ and $\zeta_{c}$ refer to the natural frequency and damping ratios in the presence of contact with the substrate. The constant $K_{e}$ is based on the permittivity of air, area of the beam, and mass of the beam.

\begin{tabular}{lc}
\hline Parameter & Value \\
\hline Natural frequency free $\left(w_{f}\right)$ & $2.1 \times 10^{4}[\mathrm{~Hz}]$ \\
Damping free $\left(\zeta_{f}\right)$ & $2 \times 10^{-2}$ \\
Gap $\left(d_{g}\right)$ & $3.8 \times 10^{-6}[\mathrm{~m}]$ \\
Maximum distance to travel & $2.6 \times 10^{-6}[\mathrm{~m}]$ \\
Constant $K_{e}(\varepsilon A / 2 m)$ & $1.9 \times 10^{-11}[\mathrm{~F} \cdot \mathrm{m} / \mathrm{kg}]$ \\
Effective spring constant & $42[\mathrm{~N} / \mathrm{m}]$ \\
Natural frequency during contact $\left(w_{c}\right)$ & $6.1 \times 10^{4}[\mathrm{~Hz}]$ \\
Damping ratio during contact $\left(\zeta_{c}\right)$ & $2 \times 10^{-1}$ \\
\hline
\end{tabular}

TABle 2: Parameters used for studying pulse position using the lumped model.

\begin{tabular}{lcc}
\hline Actuation voltage & Control voltage & Pulse width \\
\hline $30 \mathrm{~V}$ & $20 \mathrm{~V}$ & $14 \mu \mathrm{s}$ \\
\hline
\end{tabular}

TABLE 3: The parameters used for studying the actuation voltage.

\begin{tabular}{lcc}
\hline Pulse position & Control voltage & Pulse width \\
\hline $17 \mu \mathrm{s}$ & $20 \mathrm{~V}$ & $14 \mu \mathrm{s}$ \\
\hline
\end{tabular}

better result than the earlier case. To explain this phenomenon we have to look at the landing times for different actuation voltages. Also, the application of the control pulse is constant in both magnitude and time, and hence the best possible result will be achieved if control pulse is applied for the full duration of the first bounce. Figure 11 can explain this result further.

From Figure 11, it is seen that the largest reduction in velocity occurs if the control pulse (shown as a rectangular wave) is applied over the initial bounce. The application of the control voltage at high voltages does not affect velocity since the landing event occurs before the application of the control voltage.

For lower voltage, after the activation of the control voltage, the actuation voltage is reapplied. Due to the small distance between the beam and the substrate, the actuation voltage is the dominant force and hence reaccelerates the beam rapidly. This can be used to explain the presence of a minimum point in Figure 10.

Control voltage follows a similar pattern to actuation voltage with the exception that increasing the control voltage has an opposite effect to that of the actuation voltage.

By tuning the parameters presented earlier (such as in Table 1), it is possible to minimize bouncing. The tuning process for switches with different parameters will be different. Using the actuation voltage at $30 \mathrm{~V}$ and control voltage at $15 \mathrm{~V}$ and applying the control pulse from $17 \mu$ s to $27 \mu$ s, one can see that the switch shows no bouncing at all (Figure 12). As seen in Figure 12, the landing time is increased to $29 \mu$ s while the landing velocity is reduced to $0.08 \mathrm{~m} / \mathrm{s}$.
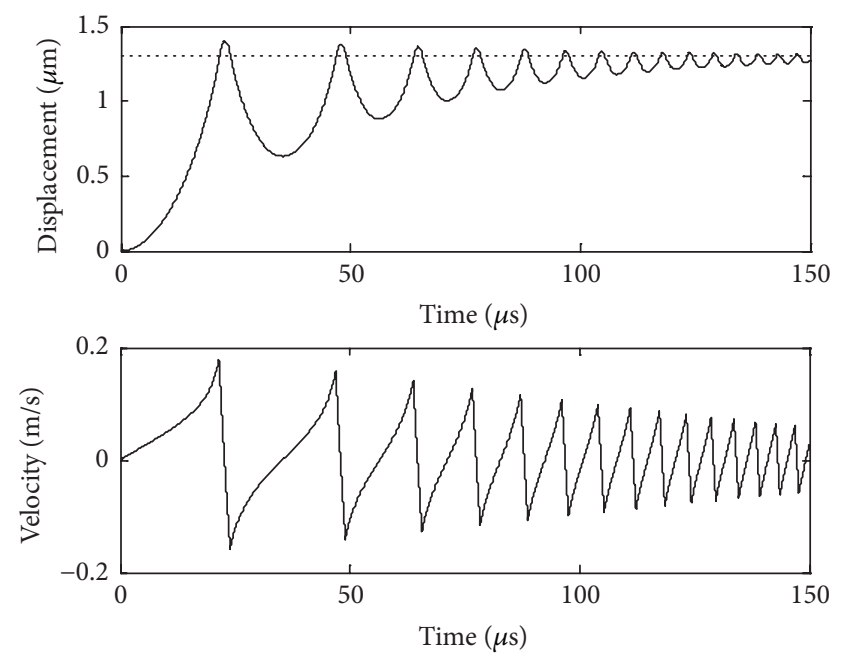

FIGURE 4: Uncontrolled bouncing and velocity characteristics.

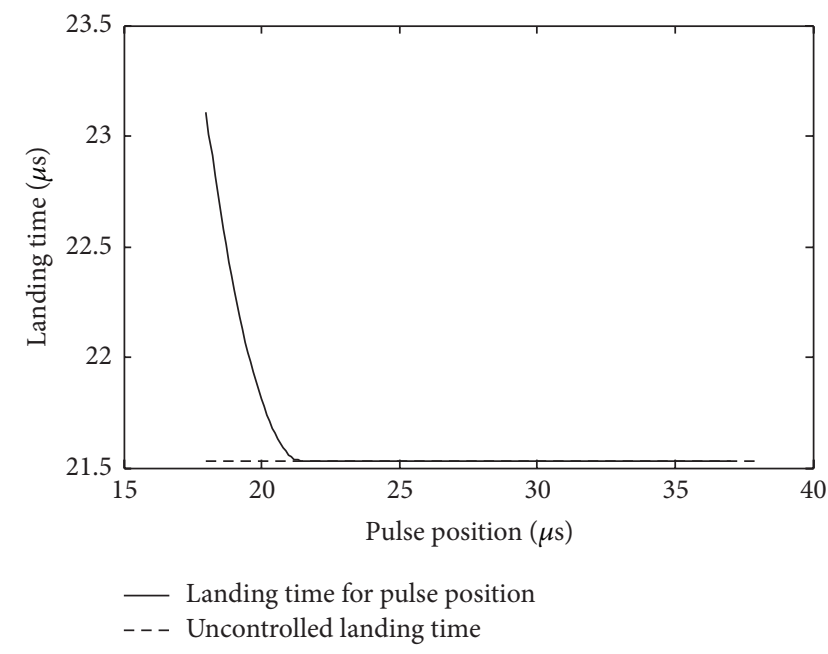

FIGURE 5: Landing time versus pulse position.

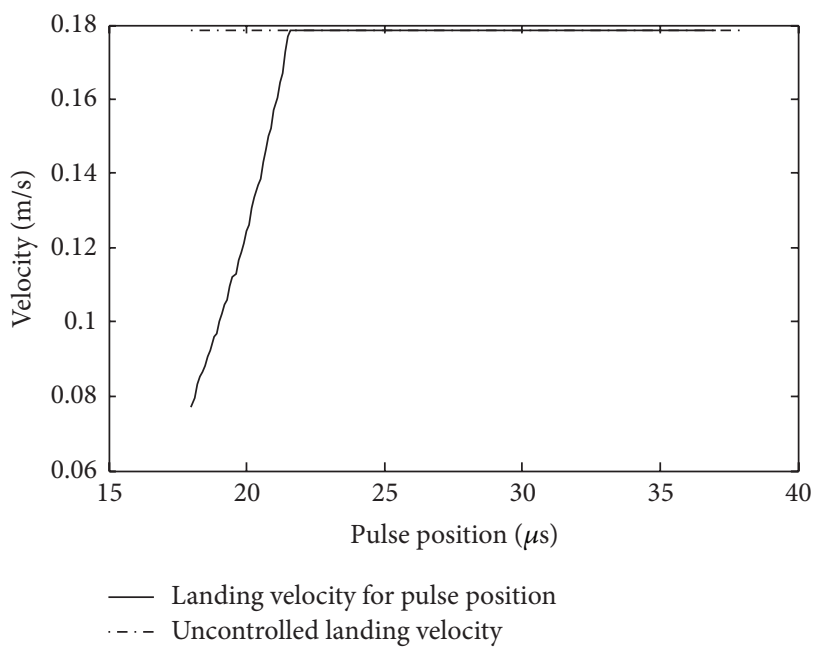

FIGURE 6: Landing velocity versus pulse position. 


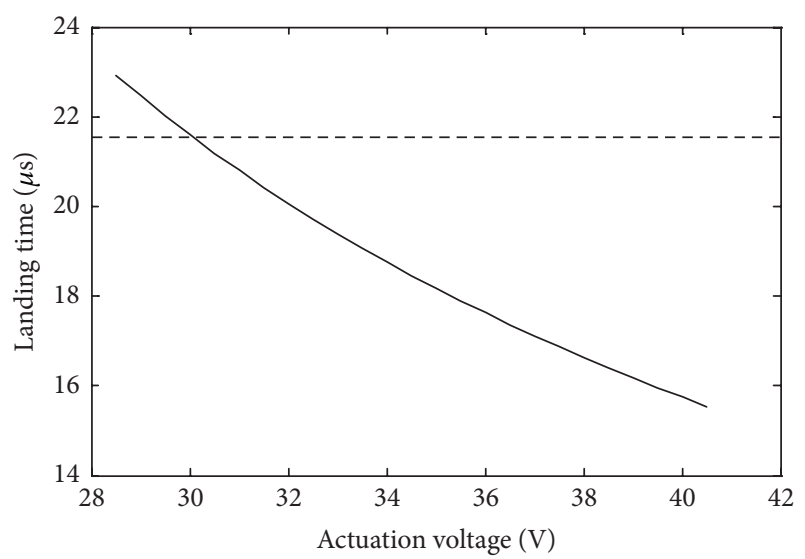

— Landing time for $V_{\mathrm{DC} 1}$

- - - Uncontrolled landing time

FIGURE 7: Landing time versus actuation voltage.

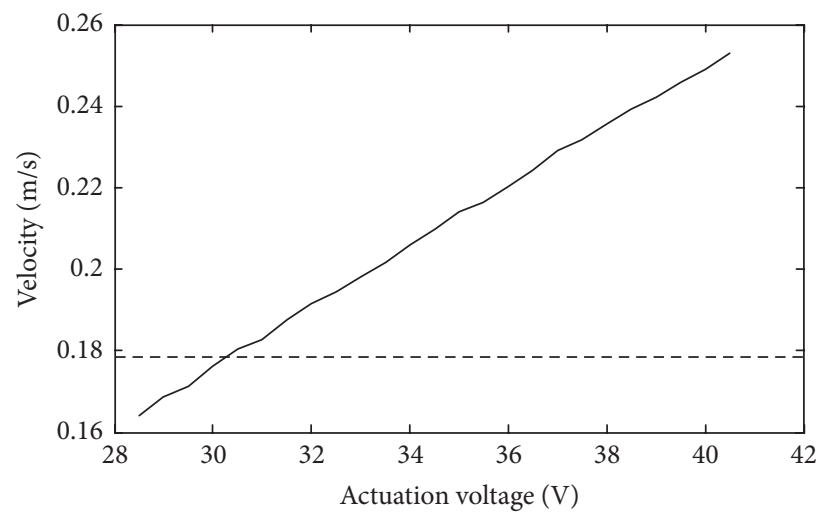

- Landing velocity for $V_{\mathrm{DC}}$

- - - Uncontrolled landing velocity

FIGURE 8: Landing velocity versus actuation voltage.

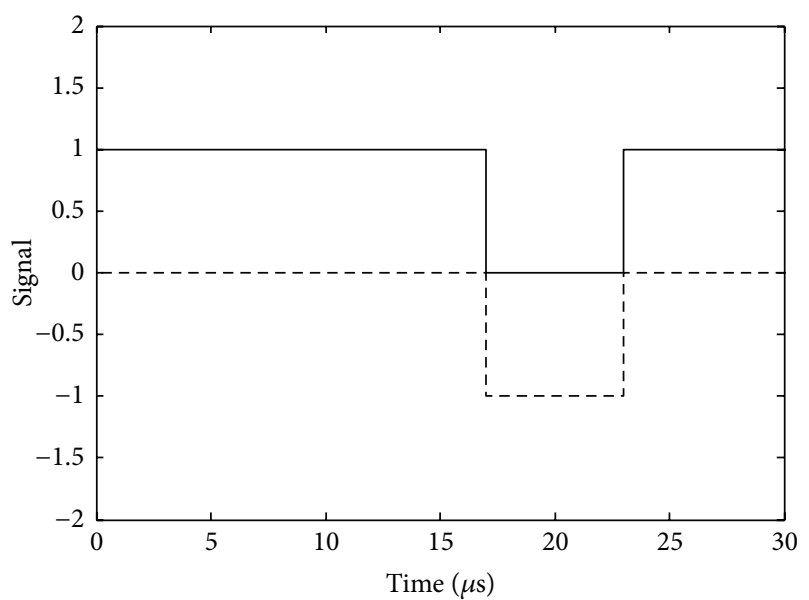

- Actuation signal

- - - Control signal

FIgURE 9: Noncontinuous application of actuation and control signal.

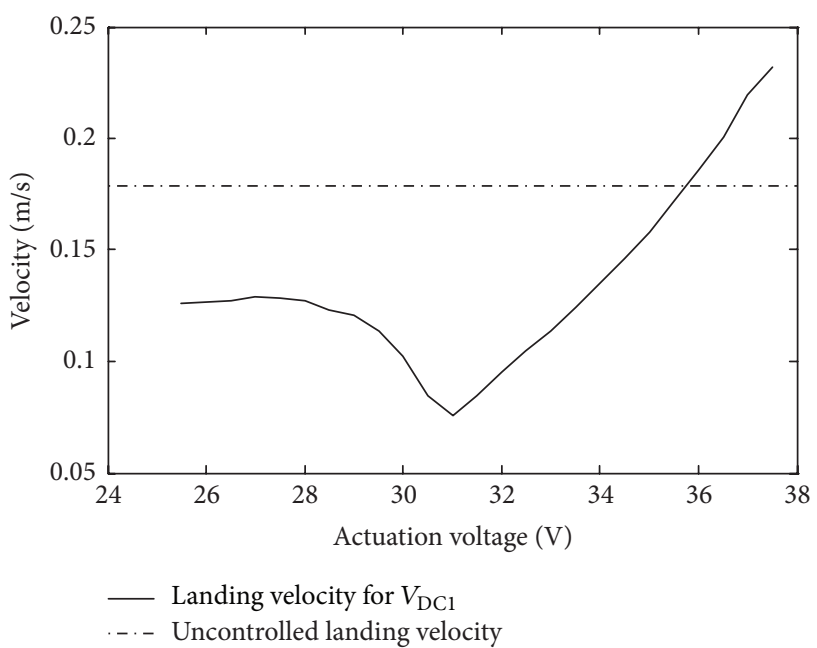

FIGURE 10: Landing velocity versus actuation voltage for the lumped parameter model for the case of noncontinuous actuation voltage.

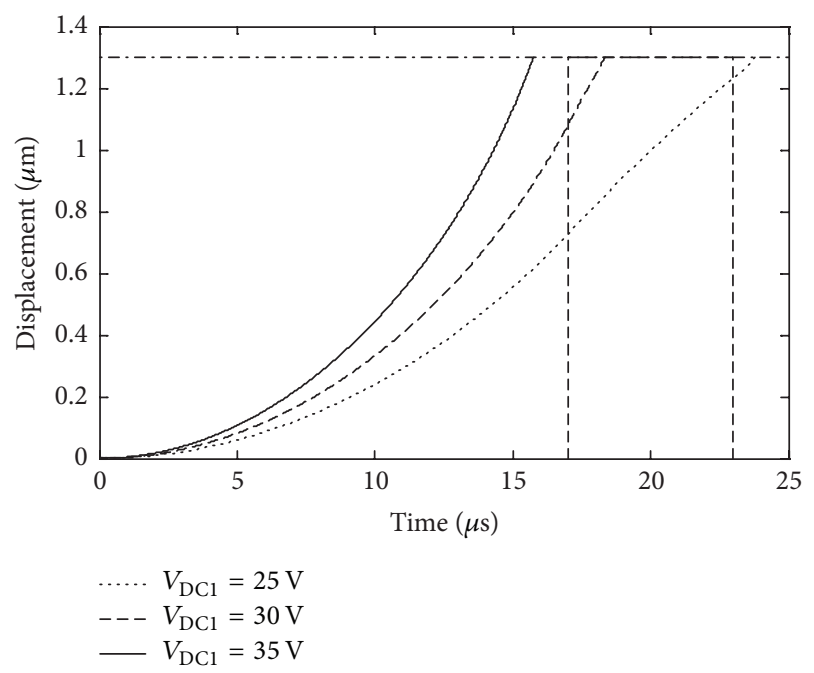

FIGURE 11: Landing times for different actuation voltages for constant control pulse parameters.
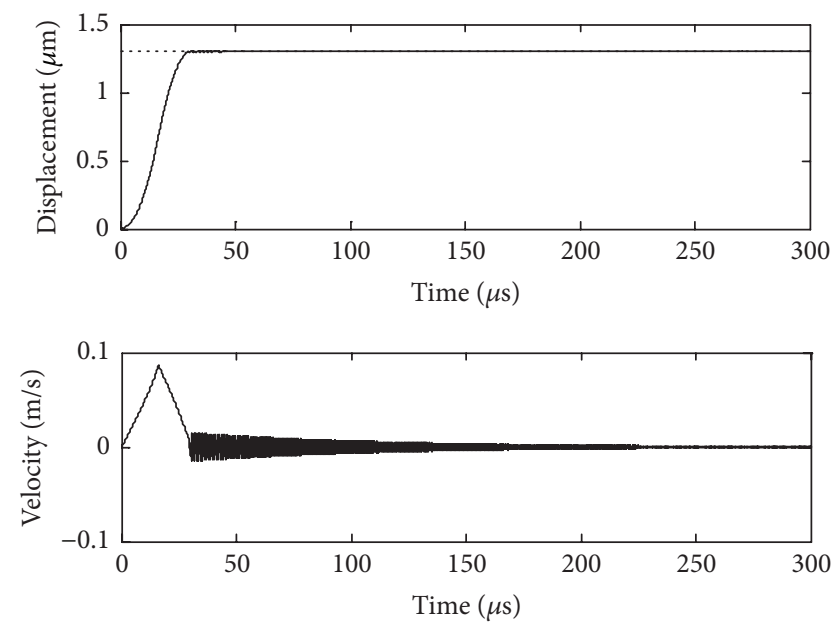

FIGURE 12: Displacement and velocity profiles for tuned system using the double-electrode scheme. 


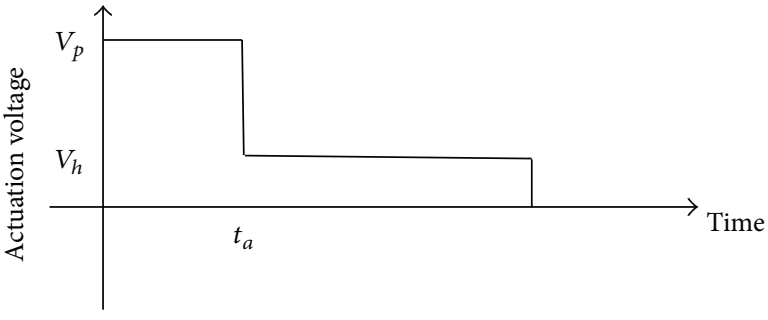

(a)

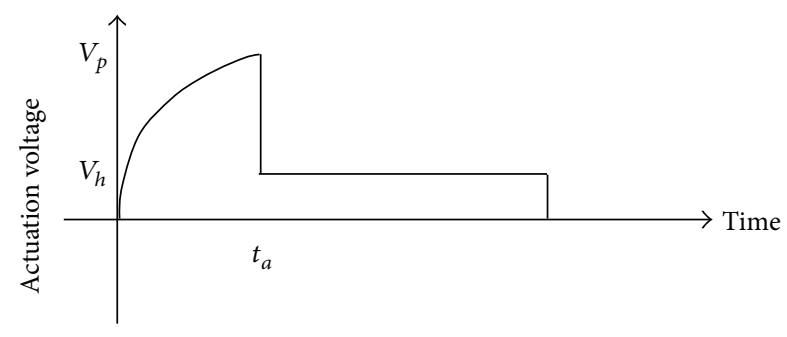

(b)

FIGURE 13: (a) Dual pulse actuation waveform (DP). (b) Exponentially increasing dual pulse actuation waveform (EDP).

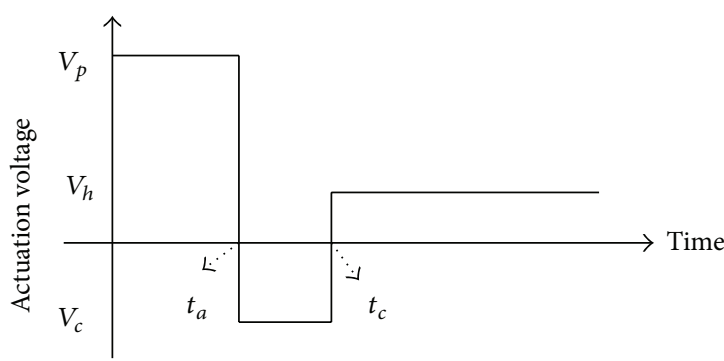

(a)

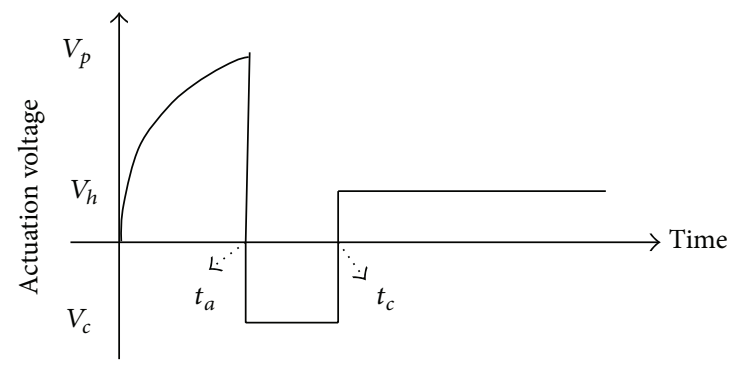

(b)

FIGURE 14: (a) Modified dual pulse actuation waveform (MDP). (b) Modified exponentially increasing dual pulse actuation waveform (MEDP).

TABLE 4: Parameters for the simulated DP and EDP waves.

\begin{tabular}{lccccc}
\hline & $t_{a}[\mu \mathrm{s}]$ & $V_{P}[\mathrm{~V}]$ & $V_{h}[\mathrm{~V}]$ & $V_{c}[\mathrm{~V}]$ & $t_{c}[\mu \mathrm{s}]$ \\
\hline DP & 17.4 & 80 & 40 & - & - \\
MDP & 17.4 & 85 & 40 & 53.1 & 19.9 \\
EDP & 26.4 & 80 & 40 & - & - \\
MEDP & 29 & 80 & 40 & 50 & 31.405 \\
\hline
\end{tabular}

3.2. Comparison with Other Control Schemes. To assess the efficiency of the double-electrode control scheme, we compare its performance with two different types of actuation waves in the literature: the dual pulse actuation waveform (DP) and the exponentially increasing dual pulse waveform (EDP) (Figure 13). These are simulated based on [10] and tested with similar parameters against the double electrode scheme. Dual pulse actuation waveform consists of an actuation voltage followed by a holding voltage. On the other hand the EDP has a similar shape with the difference being the initial actuation is achieved through exponentially increasing voltage. To allow the comparison of these waveforms with the double electrode model, we modify the waveforms with the inclusion of a control voltage $\left(V_{c}\right)$ as shown in Figure 14. The changed waveforms are labeled modified dual pulse actuation (MDP) and modified exponentially increasing dual pulse actuation waveforms (MEDP).

Table 4 shows the values used to compare DP with MDP and EDP with MEDP waveforms.

Using the data in Table 4, the displacement and velocity profiles of Figure 15 are obtained.

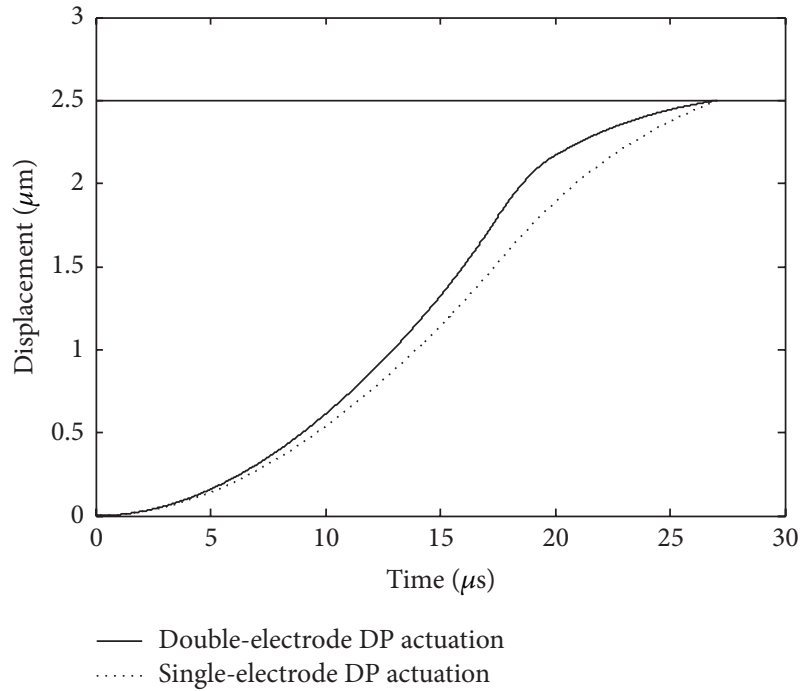

FIGURE 15: Displacement profile for DP and MDP.

From Figures 15-16, it is seen that double-electrode configuration can improve beam dynamics by reducing both landing time and landing velocity. The landing time is reduced from $27.08 \mu$ s to $26.8 \mu \mathrm{s}$. The velocity reduction is more profound and is reduced from $0.055 \mathrm{~m} / \mathrm{s}$ for singleelectrode DP to $0.022 \mathrm{~m} / \mathrm{s}$ for the double-electrode configuration MDP.

For the EDP case in Figures 17-18, landing time reduction is more profound as compared to landing velocity reduction. The landing time is reduced from $41 \mu \mathrm{s}$ to $37 \mathrm{~s}$. The velocity 


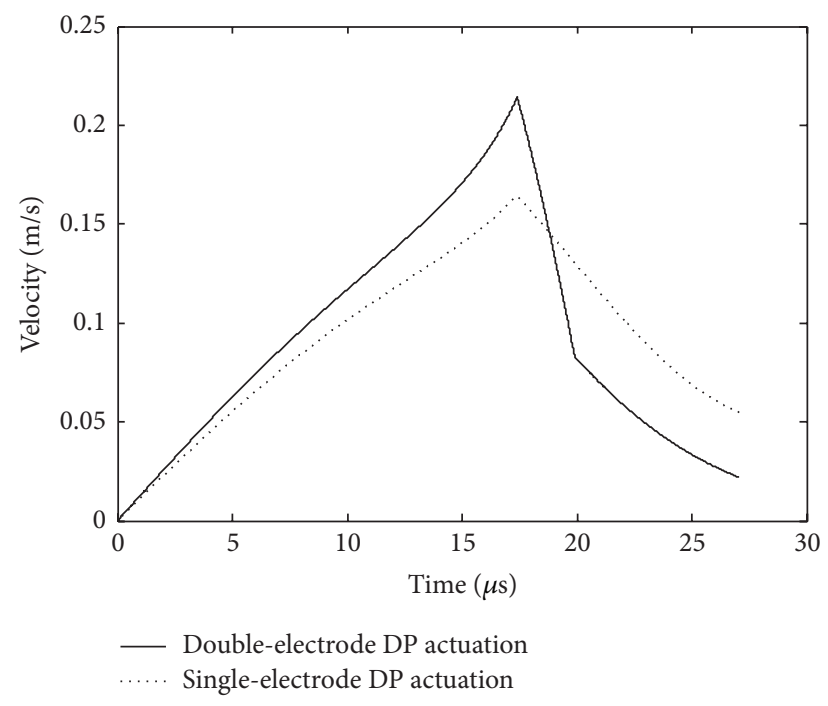

Figure 16: Velocity profile for DP and MDP.

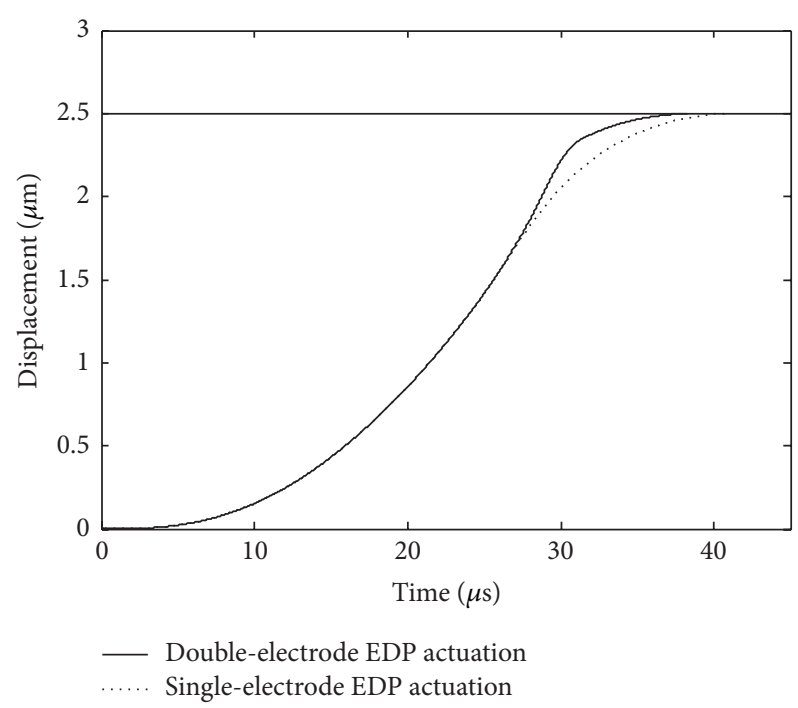

FIGURE 17: Displacement profile for EDP and MEDP.

reduces from $0.0053 \mathrm{~m} / \mathrm{s}$ for a single electrode to $0.0032 \mathrm{~m} / \mathrm{s}$ for the double-electrode configuration.

3.3. Beam Model. Double-electrode model using a continuous beam model is developed to improve the accuracy of the results. As such, the parameters of the model are taken from [2] and are provided in Table 5.

The bouncing profile obtained using the beam model for actuation voltage $280 \mathrm{~V}$ and control voltage $0 \mathrm{~V}$ (uncontrolled response) is given in Figure 19.

When varying the application time of the pulse, Figures 20-21 are obtained.

As in the case of lumped parameter system, the beam model shows similar results for landing time and landing velocity. For Figure 20, voltages are set at $280 \mathrm{~V}$ and $110 \mathrm{~V}$ for

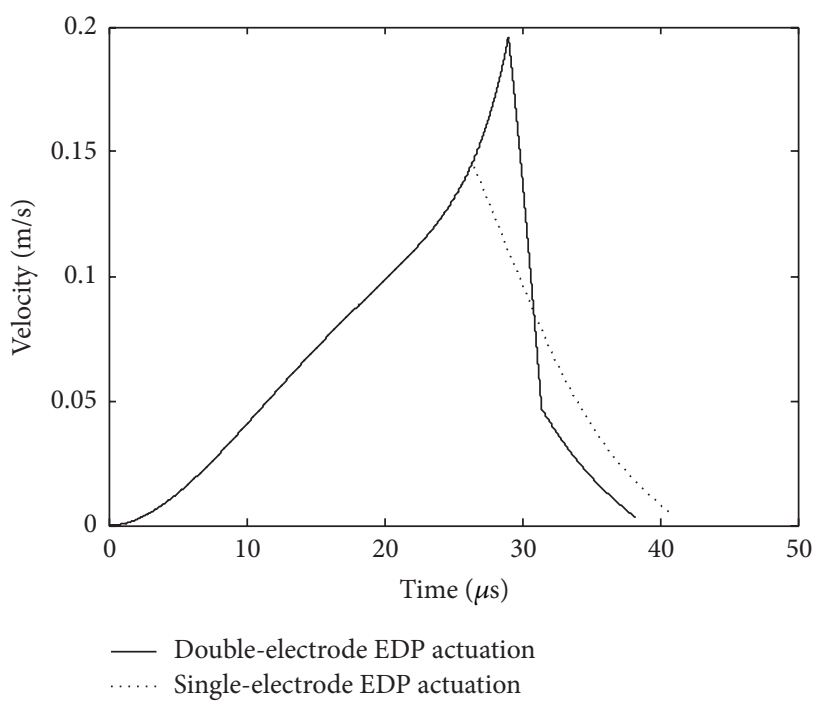

FIGURE 18: Velocity profile for EDP and MEDP.

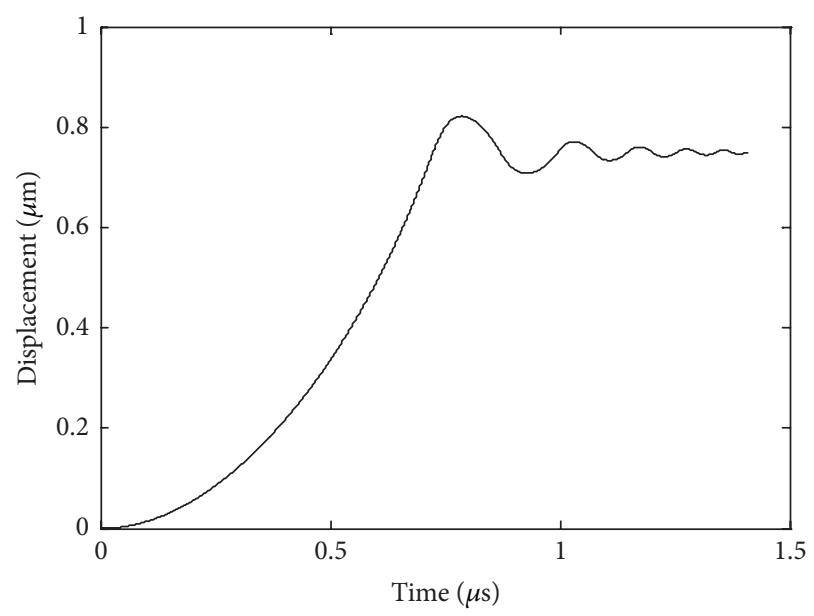

FIGURE 19: Uncontrolled bouncing characteristics.

TABle 5: Parameters used for the beam model [2].

\begin{tabular}{lc}
\hline Parameter & Value \\
\hline Length & $70[\mu \mathrm{m}]$ \\
Width & $30[\mu \mathrm{m}]$ \\
Thickness & $2[\mu \mathrm{m}]$ \\
Gap $\left(d_{g}\right)$ & $1.5[\mu \mathrm{m}]$ \\
Max distance $\left(d_{t}\right)$ & $0.75[\mu \mathrm{m}]$ \\
Electrode position & $21[\mu \mathrm{m}]$ to $49[\mu \mathrm{m}]$ \\
Young's modulus $(E)$ & $207[\mathrm{GPa}]$ \\
Density & $8900\left[\mathrm{~kg} / \mathrm{m}^{3}\right]$ \\
\hline
\end{tabular}

control and actuation voltages, respectively. The pulse width is set to $0.21 \mu \mathrm{s}$.

Similar to the lumped parameter model, it is possible to tune the system to get reduced overall bouncing and landing velocity in the beam. Tuning is a dynamic process and requires use of the results derived earlier in the form of the 


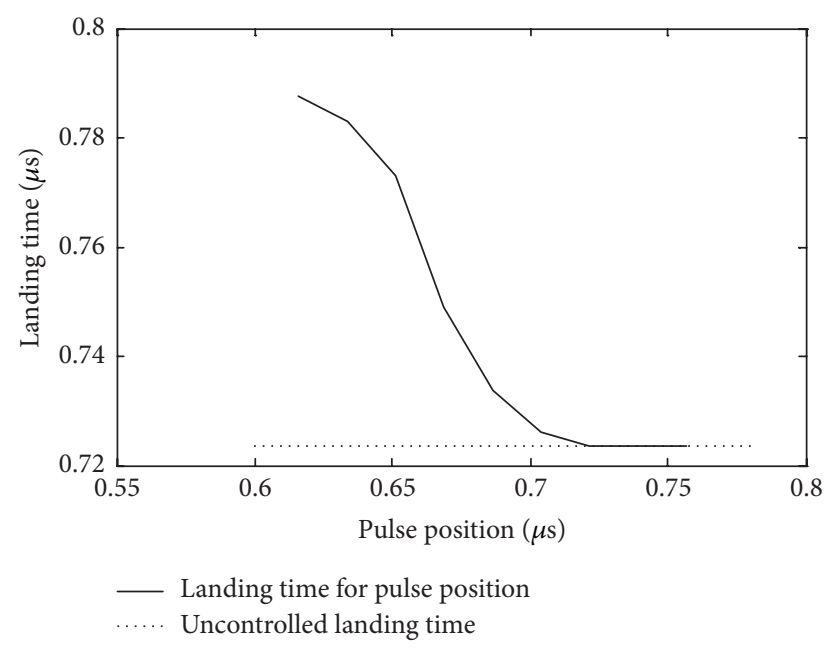

FIGURE 20: Landing time versus pulse position.

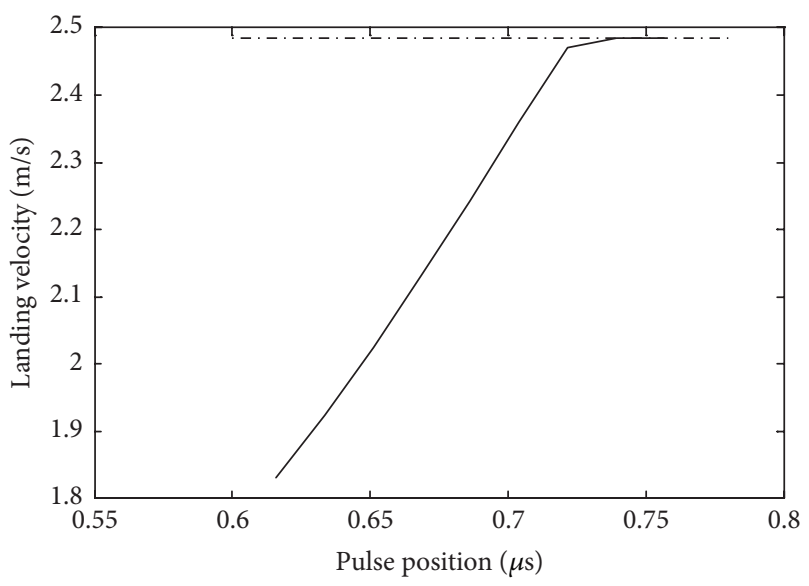

_ Landing velocity for pulse position

...- Uncontrolled landing velocity

FIGURE 21: Landing velocity versus pulse position.

TABLE 6: Parameters used for obtaining tuned system.

\begin{tabular}{lccc}
\hline Actuation voltage & Control voltage & Pulse width & Pulse position \\
\hline $300 \mathrm{~V}$ & $200 \mathrm{~V}$ & $0.13 \mu \mathrm{s}$ & $0.36 \mu \mathrm{s}$
\end{tabular}

models response to different parameters. Table 6 shows the tuning parameters chosen to minimize the beam bouncing. The result can be seen in Figure 22. Compared to Figure 19, Figure 22 shows the beam tip displaces much less and settles faster with tuning.

Table 6 shows the parameters used to obtain the least landing velocity and bouncing characteristics.

From Figure 22, one can see that the overall bouncing is reduced. The landing velocity (not shown) is also reduced from a normalized value of 2.06 to 1.78 .

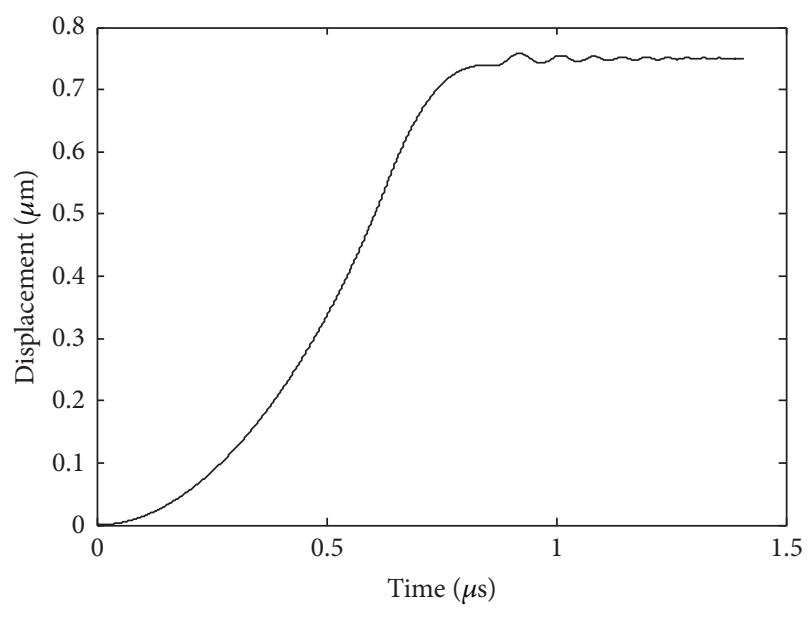

FIgURE 22: Tuned displacement profile for the beam model.

\section{Conclusions}

This paper discusses a method that can allow the users to actively tune their devices to obtain the required landing time and velocities up to the limitations allowed by the physics of the system. The dual electrode configuration hence has practical use as it may be easily tuned as compared to other techniques that may require extensive simulations for each switch, as switches even in the same wafer may have wide variations in the parameters. The switch used for the simulations in this paper is a double-electrode switch. Similar to the single-electrode switch, one electrode is used for the actuation of the switch towards the gate. However, an extra electrode (the control electrode) is used to decelerate the beam to control bouncing. The lumped model for the double electrode was simulated and the dependence on the switch landing time and velocity has been modeled. Furthermore, the beam model for the system was also derived to seek more accurate results. Simulations done on the system confirmed that the switch of this form may be used to reduce bouncing and high landing velocities.

\section{Nomenclature}

$m: \quad$ Effective mass $/ \mathrm{kg}$

$c: \quad$ Damping coefficient $[\mathrm{Ns} / \mathrm{m}]$

$k: \quad$ Effective stiffness/[N/m]

$\varepsilon: \quad$ Permittivity of free space/[F/m]

A: $\quad$ Area of electrode $\left[\mathrm{m}^{2}\right]$

$d: \quad$ Substrate-beam gap $/ \mathrm{m}$

E: Young's modulus/Pa

I: $\quad$ Moment of inertia $/ \mathrm{m}^{4}$

$\rho: \quad$ Density $/\left[\mathrm{kg} / \mathrm{m}^{3}\right]$

$w(x, t):$ Beam deflection $/ \mathrm{m}$

$\phi(x)$ : Mode shape

$u(t)$ : Modal coordinate

$K_{e}: \quad$ Electrostatic constant $=\varepsilon A / 2 m[\mathrm{Fm} / \mathrm{kg}]$

$\zeta: \quad$ Damping ratio. 


\section{Competing Interests}

There is no conflict of interests among the authors. This paper is based on this thesis titled "Control of Bouncing in RF MEMS Switches Using Double Electrode" written by the first author.

\section{Acknowledgments}

This work has been supported by KAUST.

\section{References}

[1] H. Sumali, J. E. Massad, D. A. Czaplewski, and C. W. Dyck, "Waveform design for pulse-and-hold electrostatic actuation in MEMS," Sensors and Actuators, A: Physical, vol. 134, no. 1, pp. 213-220, 2007.

[2] B. McCarthy, G. G. Adams, N. E. McGruer, and D. Potter, "A dynamic model, including contact bounce, of an electrostatically actuated microswitch," Journal of Microelectromechanical Systems, vol. 11, no. 3, pp. 276-283, 2002.

[3] C. Do, M. Lishchynska, M. Cychowski, K. Delaney, and M. Hill, "Energy-based approach to adaptive pulse shaping for control of RF-MEMS DC-contact switches," Journal of Microelectromechanical Systems, vol. 21, no. 6, Article ID 6262437, pp. 1382-1391, 2012.

[4] T. Wang and S. F. Asokanthan, "Bouncing dynamics in MEMSbased switching structures," in Proceedings of the 7th European Nonlinear Dynamics Conference (ENOC '11), Rome, Italy, July 2011.

[5] D. A. Czaplewski, C. W. Dyck, H. Sumali et al., "A soft-landing waveform for actuation of a single-pole single-throw ohmic RF MEMS switch," Journal of Microelectromechanical Systems, vol. 15, no. 6, pp. 1586-1594, 2006.

[6] J. C. Blecke, D. S. Epp, H. Sumali, and G. G. Parker, "A simple learning control to eliminate RF-MEMS switch bounce," Journal of Microelectromechanical Systems, vol. 18, no. 2, pp. 458-465, 2009.

[7] C. H. Lai and W. S. H. Wong, "A comparison between voltage waveforms to enhance the lifetime of MEMS switch," in Proceedings of the 37th Annual Conference of the IEEE Industrial Electronics Society (IECON '11), pp. 2082-2087, IEEE, Melbourne, Australia, November 2011.

[8] A. Peschot, C. Poulain, N. Bonifaci, and O. Lesaint, "Contact bounce phenomena in a MEM switch," in Proceedings of the IEEE 58th Holm Conference on Electrical Contacts (Holm), pp. 1-7, Portland, Ore, USA, September 2012.

[9] A. Jain, P. R. Nair, and M. A. Alam, "Strategies for dynamic soft-landing in capacitive microelectromechanical switches," Applied Physics Letters, vol. 98, no. 23, Article ID 234104, 2011.

[10] W. S. Wong and C. H. Lai, "Mitigation of MEMS switch contact bouncing: effectiveness of dual pulse actuation waveforms and robustness against variations in switch and waveform parameters," Sensors and Actuators A: Physical, vol. 194, pp. 188195, 2013.

[11] M. Spasos and R. Nilavalan, "On the investigation of a reliable actuation control method for ohmic RF MEMS switches," Microelectronics Journal, vol. 42, no. 11, pp. 1239-1251, 2011.

[12] R. C. Tung, A. Fruehling, D. Peroulis, and A. Raman, "Multiple timescales and modeling of dynamic bounce phenomena in
RF MEMS switches," Journal of Microelectromechanical Systems, vol. 23, no. 1, pp. 137-146, 2014.

[13] H. F. Dadgour, M. M. Hussain, C. Smith, and K. Banerjee, "Design and analysis of compact ultra energy-efficient logic gates using laterally-actuated double-electrode NEMS," in Proceedings of the 47th ACM/IEEE Design Automation Conference (DAC '10), pp. 893-896, ACM, Austin, Tex, USA, June 2010.

[14] F. M. Alsaleem and M. I. Younis, "Stabilization of electrostatic MEMS resonators using a delayed feedback controller," Smart Materials and Structures, vol. 19, no. 3, Article ID 035016, 2010.

[15] F. M. Alsaleem and M. I. Younis, "Integrity analysis of electrically actuated resonators with delayed feedback controller," Journal of Dynamic Systems, Measurement and Control, vol. 133, no. 3, Article ID 031011, 8 pages, 2011.

[16] S. Shao, K. M. Masri, and M. I. Younis, "The effect of timedelayed feedback controller on an electrically actuated resonator," Nonlinear Dynamics, vol. 74, no. 1, pp. 257-270, 2013.

[17] K. M. Masri, S. Shao, and M. I. Younis, "Delayed feedback controller for microelectromechanical systems resonators undergoing large motion," JVC/Journal of Vibration and Control, vol. 21, no. 13, pp. 2604-2615, 2015.

[18] H. Yagubizade and M. I. Younis, "The effect of squeezefilm damping on the shock response of clamped-clamped microbeams," Journal of Dynamic Systems, Measurement and Control, vol. 134, no. 1, Article ID 011017, 7 pages, 2012.

[19] M. I. Younis, MEMS Linear and Nonlinear Statics and Dynamics, vol. 20, Springer, 2011. 


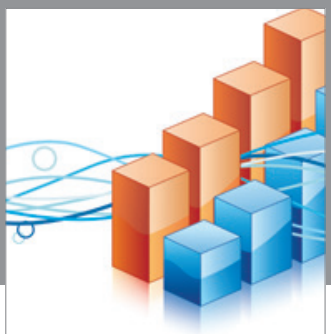

Advances in

Operations Research

vatem alat4

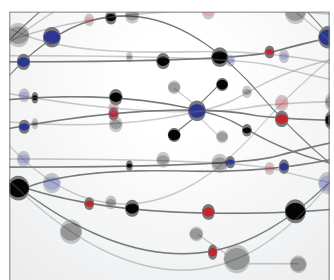

\section{The Scientific} World Journal
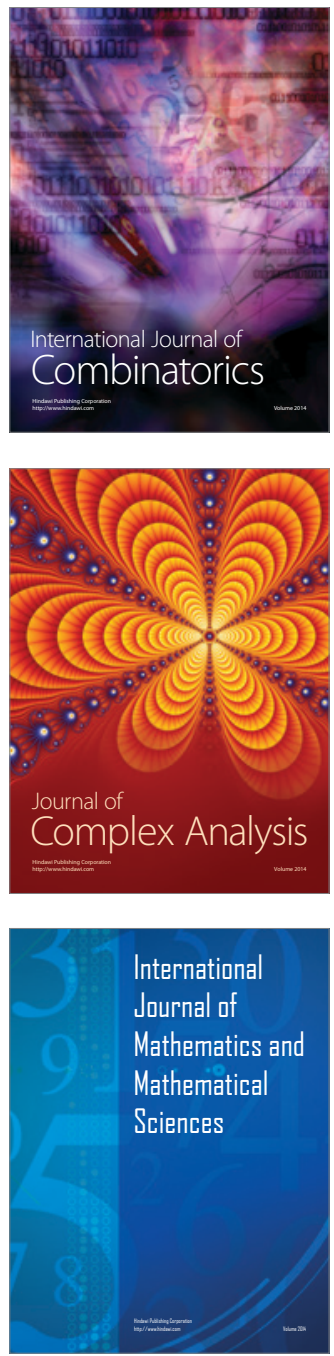
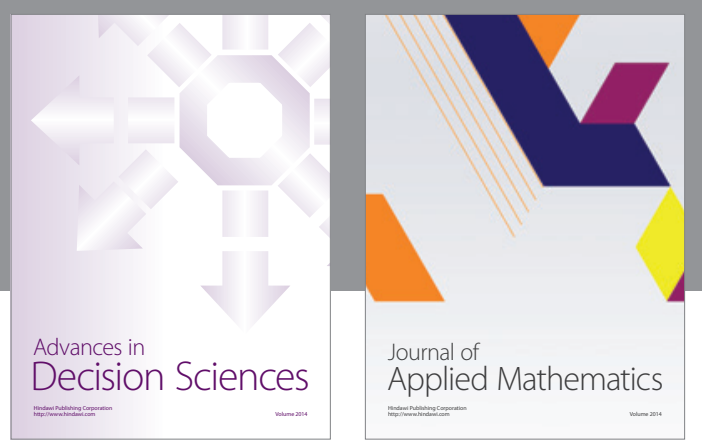

Algebra

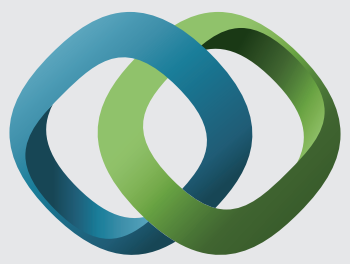

\section{Hindawi}

Submit your manuscripts at

http://www.hindawi.com
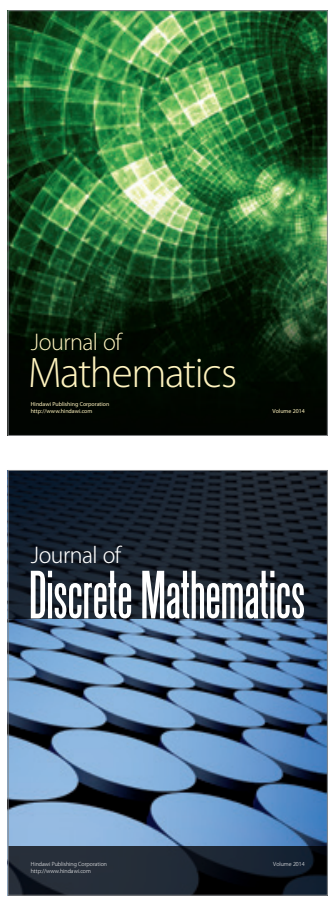

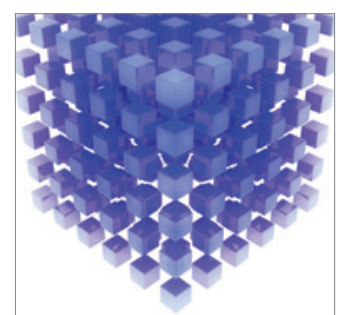

Mathematical Problems in Engineering
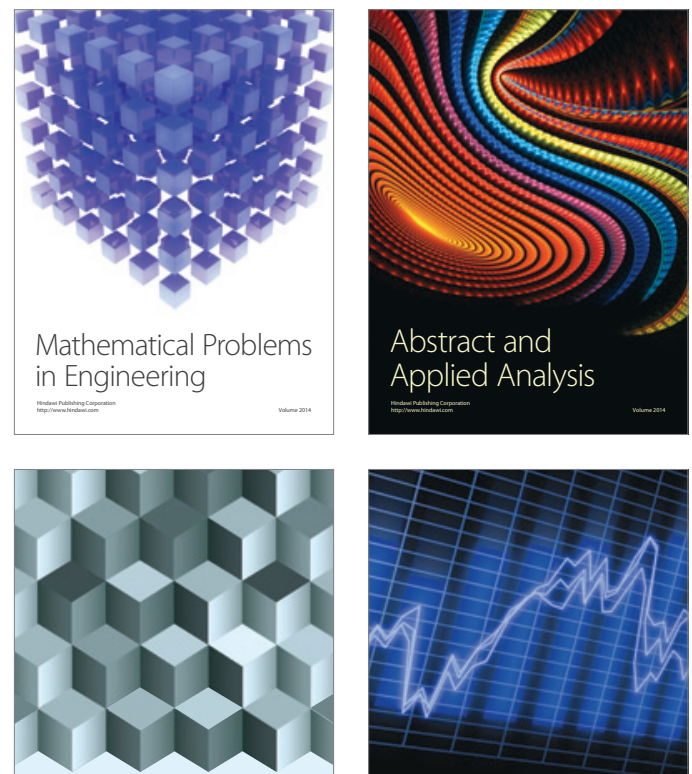

Journal of

Function Spaces

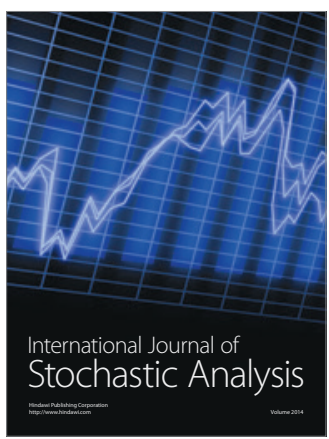

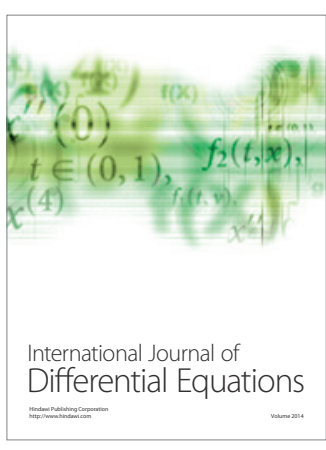
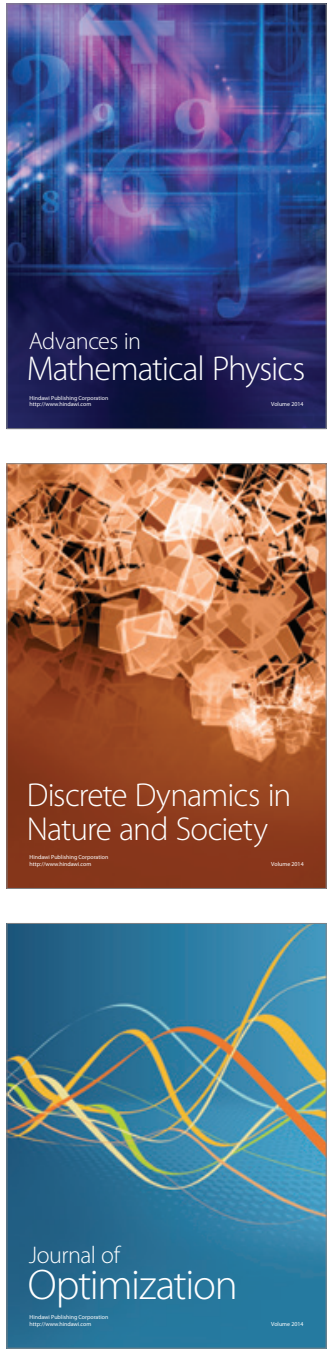